\title{
(5) \\ O ENVELHECIMENTO POPULACIONAL NA SOCIEDADE CAPITALISTA: ENTRE O SOCIAL E O ECONÔMICO
}

\author{
Population aging in capitalist society: between the social and the economic
}

\author{
Milena da Silva Santos* \\ https://orcid.org/0000-0002-1438-4928 \\ Michelli Barbosa do Nascimento** \\ https://orcid.org/0000-0003-0476-4393.
}

\begin{abstract}
RESUMO
Este texto trata das implicações do envelhecimento populacional na sociedade capitalista. Tem como objetivo evidenciar os aspectos sociais e econômicos do processo do envelhecimento, tanto no trato da pessoa idosa pela sociedade e pelo Estado quanto no potencial mercadológico pelo sistema econômico. Para tanto, respalda-se no referencial teórico-metodológico crítico-dialético, através de pesquisa bibliográfica e documental. Assim, apresenta reflexões sobre o envelhecimento demográfico no capitalismo contemporâneo e a relação capitalista no processo de envelhecimento populacional, destacando o mercado consumidor crescente voltado para esta população e o mercado de trabalho, no processo de exploração do trabalho deste segmento; como também analisa as conquistas alcançadas e os desafios a serem enfrentados pela sociedade e pela população idosa diante da crise do capital e das reformas das políticas sociais. Compreende que apesar dos avanços dos direitos sociais garantidos a esse segmento populacional, estes estão ameaçados com o fortalecimento do neoliberalismo no Estado brasileiro.
\end{abstract}

PALAVRAS-CHAVE: Envelhecimento. Capitalismo. Sociabilidade.

\begin{abstract}
This text deals with the implications of population aging on capitalist society. It aims to highlight the social and economic aspects of the aging process, both in the treatment of the elderly by society and the state and in the market potential by the economic system. Therefore, it is supported by the critical-dialectical theoretical-methodological framework, through bibliographic and documentary research. Thus, it presents reflections on the demographic aging in contemporary capitalism and the capitalist relationship in the population aging process, highlighting the growing consumer market aimed at this population and the labor market, in the process of exploiting the work of this segment; It also analyzes the achievements and

\footnotetext{
* Assistente social. Mestre em Serviço Social. Doutoranda em Serviço Social da Universidade Federal do Rio Grande do Norte (UFRN, Natal, Brasil). Centro de Ciências Sociais Aplicadas - Departamento de Serviço Social; Sala 32. Setor de aulas V. Bairro: Lagoa Nova, Natal (RN). E-mail: milena_sso@hotmail.com.

${ }^{* *}$ Assistente social. Mestre em Gerontologia pela Universidade Federal de Pernambuco (UFPE). Assistente social do Programa Hospital, em Casa/Hospital Agamenon Magalhães. Estr. do Arraial, 2723, Casa Amarela, Recife (PE).E-mail: michellibnascimentoas@gmail.com.
}

DOI 10.22422/temporalis.2020v20n39p84-101 Commons Atribuição 4.0 Internacional (https://creativecommons.org/licenses/by/4.o/deed.pt_BR), que permite copiar e redistribuir o material em qualquer suporte ou formato, bem como adaptar, transformar e criar a partir deste material para qualquer fim, mesmo que comercial. O licenciante não pode revogar estes direitos desde que você respeite os termos da licença

Temporalis, Brasília (DF), ano 20, n. 39, p. 163-176, jan./jun. 2020. | ISSN 2238-1856 
challenges to be faced by society and the elderly population in the face of the capital crisis and social policy reforms. He understands that despite the advances in social rights guaranteed to this population segment, they are threatened with the strengthening of neoliberalism in the Brazilian State.

KEYWORDS: Aging. Capitalism. Society.

\section{INTRODUÇÃO}

A s atuais formas de domínio da produção da riqueza material da sociedade permitiram aos indivíduos alcançar um patamar novo de vivência e de relações sociais. O modo de produção capitalista revolucionou a capacidade de fortalecimento das forças produtivas, como nunca se imaginou antes. Um dos aspectos positivos do capital é a possibilidade de satisfação das necessidades materiais e sociais em escala crescente. Porém, este sistema não tem como referência as necessidades humanas, e sim as necessidades de lucro. Ele é orientado para a expansão e movido pela acumulação.

Entre os aspectos negativos do sistema do capital estão a geração de riqueza material crescente e, paralelamente, o crescimento da miséria - o que Karl Marx (1988) denominou de Lei Geral da Acumulação Capitalista'. Esse sistema também proporcionou condições para a geração de um contingente populacional em expansão que não encontra lugar efetivo na esfera da produção material (uma população relativamente supérflua).

Diante da realidade atual, de alcance do estágio maduro do capitalismo, percebe-se que suas contradições não podem ser mais remediadas ou deslocadas para outras esferas sociais. Elas devem ser encaradas como parte do processo de totalidade social, construído sob a égide do modo de produção. Em meio a esses aspectos, observa-se o crescimento populacional, assim como o crescimento acelerado da população idosa, em todo o mundo.

A proposta aqui é analisar os aspectos sociais e econômicos do processo do envelhecimento a partir de uma concepção crítico-dialética, na perspectiva de compreender o processo de envelhecimento e velhice para além dos aspectos biológicos, cronológicos e demográficos. Não se trata, portanto, conforme Paiva (2012) afirma,

[...] do processo de envelhecimento humano em seu entendimento 'natural', 'atemporal' e 'global', mas da velhice produzida no âmbito da sociedade moderna. Trata-se, escrito de outra maneira, da velhice reproduzida nos limites das condições concretas no espaço e no compasso do tempo do capital (PAIVA, 2012, p. 30).

Vale ressaltar que nas últimas décadas a sociedade brasileira está envelhecendo em escalas alarmantes, adquirindo, assim, o status de fenômeno mundial, considerado um marco na história da humanidade. Todavia, tal privilégio transforma-se também em desafio para

\footnotetext{
${ }^{1}$ No capítulo XXIII, de O Capital, Karl Marx apresenta uma análise dos fundamentos sócio históricos do capitalismo. O autor trata do processo de acumulação do capital, das leis que o determinam e dos efeitos gerados para a classe trabalhadora. Sinteticamente, a Lei Geral da Acumulação Capitalista, é o processo pelo qual o capital gera riqueza material crescente e, ao mesmo tempo, a miséria da classe trabalhadora.
}

Temporalis, Brasília (DF), ano 20, n. 39, p. 163-176, jan./jun. 2020. | ISSN 2238-1856 
diversas nações, haja vista que a "questão social”, característica da sociedade capitalista, é um fator que marca a realidade de muitos indivíduos, inviabilizando a realização de suas necessidades básicas e potencialidades humanas.

Não se pode negar o conjunto de representações sobre a velhice presentes nos discursos produzidos pela gerontologia social, pelo Estado e pela sociedade moderna. Representações essas que, segundo Haddad (2016), ocultam a realidade vivida pelos homens e mulheres envelhecidos, ou seja, que a velhice é também o produto da existência objetiva do ser humano.

As reflexões aqui postas buscam apreender a nova realidade representada pelo progressivo aumento da população idosa e de suas necessidades sociais, bem como os desafios para a formatação da agenda pública estatal em termos da conformação de políticas, programas e serviços que considerem e absorvam as suas especificidades. Buscase fazer a relação dos aspectos sociais e econômicos.

Para tanto, reflete-se a partir do referencial teórico-metodológico crítico-dialético, através de pesquisa bibliográfica e documental, destacando os seguintes pontos: a questão do envelhecimento demográfico no capitalismo contemporâneo; a relação capitalista no processo de envelhecimento populacional, analisando o espaço mercadológico voltado para esta população; o processo de exploração do trabalho deste segmento; por fim, as conquistas alcançadas e os desafios enfrentados pela sociedade e pela população idosa.

Tais reflexões buscam contribuir para as análises na área das ciências sociais aplicadas sobre a problemática, bem como para a categoria do Serviço Social, a qual atua diretamente nas políticas sociais.

\section{O ENVELHECIMENTO DEMOGRÁFICO NO CONTEXTO DO CAPITALISMO CONTEMPORÂNEO}

Na contemporaneidade, o envelhecimento demográfico ${ }^{3}$ tem se consolidado como uma tendência mundial. Todavia, ele se mostra um fenômeno multifacetado, complexo e heterogêneo, pois apesar de o envelhecimento populacional ser um avanço social identificado em alguns países do mundo, não é fato consolidado em alguns países de capitalismo periférico.

Dados do ano de 2013 do Programa das Nações Unidas para o Desenvolvimento (PNUD, 2014) demonstram que na Nigéria, país com baixo Índice de Desenvolvimento Humano (IDH), a faixa da população com mais de 65 anos não ultrapassa 0,5\%, enquanto na Alemanha essa população idosa contempla 17,5\% do contingente populacional. Já no Brasil, segundo pesquisa do Instituto Brasileiro de Geografia e Estatística (IBGE), a população idosa totaliza 13\% (INSTITUTO BRASILEIRO DE GEOGRAFIA E ESTATÍSTICA, 2012).

\footnotetext{
${ }^{2}$ A nosso ver, a "questão social" se refere a um complexo social, um conjunto de problemas econômicos, políticos, sociais e culturais derivados da relação contraditória entre capital e trabalho na sociabilidade capitalista.

3 O envelhecimento do perfil demográfico se dá pelo crescimento significativo do número de velhos nas sociedades, se comparado ao número de crianças e jovens, seguido pelo aumento da expectativa de vida.
}

Temporalis, Brasília (DF), ano 20, n. 39, p. 163-176, jan./jun. 2020. | ISSN 2238-1856 
Diante disso, ressalta-se a necessidade de um entendimento crítico e social sobre o processo de envelhecimento e velhice, visto que "[...] o envelhecimento populacional, longe de ser um dado natural, se configura como resultado da reprodução do sistema do capital" (PAIVA, 2014, p. 125). Ou seja, a velhice não se trata somente de uma série de mudanças nos fatores genético-biológicos ao longo do tempo cronológico.

É possível ver em estudos como os de Beauvoir (1990), Haddad (2001), Teixeira (2008) e Paiva (2014) que a velhice implica um aspecto não só biológico, mas uma produção social; "[...] é o resultado e o prolongamento de um processo" (BEAUVOIR, 1990, p. 10). Este processo é ocasionado também devido às condições objetivas de vida e trabalho, de acordo com os condicionantes e determinantes sociais.

Nessa perspectiva, concorda-se com Teixeira quando este afirma que as “[...] circunstâncias socioeconômicas, e de forma mais ampla, a posição de classe, além de fatores psicológicos, culturais, genético-biológicos, criam distinções no modo como se envelhece" (TEIXEIRA, 2017, p. 32). Porém, ressalta-se que tal perspectiva não é consensual nem hegemônica no campo da Gerontologia Social.

O crescimento acelerado da população idosa e o declínio da taxa de natalidade, aliados às circunstâncias citadas no parágrafo anterior, interferem diretamente no planejamento e na execução das ações direcionadas a esse público. Exigem-se, portanto, novas posturas tanto do poder público quanto da sociedade civil, para que haja ações sociais consistentes que englobem as múltiplas questões impostas pelas transições demográficas.

É fundamental lembrar que os indicadores sociais do envelhecimento estão sendo incrementados no momento de um encolhimento do Estado moderno, diante das suas responsabilidades para com o público aqui estudado, no cenário pleno de desregulamentação dos direitos sociais conquistados historicamente (PAIVA, 2014).

Os dados fornecidos pela Organização das Nações Unidas (ONU) revelam que a população idosa tem crescido de forma expressiva. Em 2000 o número estimado de pessoas com 60 anos ou mais era de 605 milhões; em 2011 passou para 893 milhões; e há uma perspectiva para em 2050 atingir 2 bilhões de idosos em todo o mundo. Neste período, há a probabilidade de os idosos se equipararem em número com a população infantil de 0-14 anos: “[...] O crescimento da população idosa e o declínio da infantil irão marcar a primeira vez na história em que o número de crianças e pessoas idosas será semelhante" (ONU 20012012 apud PAIVA, 2014, p. 25).

O privilégio da longevidade ainda é restrito a algumas parcelas da população mundial. Paiva (2014) apresenta os dados do relatório de Organização Mundial da Saúde (2003), através dos quais denuncia a deterioração das condições de saúde em países da África. Assim, constata que, enquanto uma criança nascida no Japão, em 2003, esperava viver, em média, 85 anos, uma criança em Serra Leoa provavelmente não viveria além dos 36 anos.

Segundo Teixeira (2008), a abordagem do envelhecimento humano deve partir do pressuposto da expressão da "questão social", atribuindo centralidade à problemática social do envelhecer do trabalhador, e não como uma circunstância inexorável que atinge a todo o grupo etário, independentemente de como a força de trabalho é expropriada e explorada. A referida autora acrescenta ainda que a problemática social que envolve o 
processo de envelhecimento, em relação ao crescente número de pessoas idosas, não representa uma ameaça à ordem política, mas sim pressões sociais que através de lutas congregam reivindicações, passando a ser introduzidas às políticas sociais públicas. Todavia, percebe-se que estas ainda precisam avançar para atender as demandas surgidas na velhice, de modo geral.

De acordo com Louvison e Rosa (2012), a expressividade do aumento populacional e, consequentemente, a sobrevida do velho trabalhador são marcadas por expressões da "questão social" que acompanham outros segmentos etários, o que redobra a dificuldade em dar respostas adequadas às necessidades do segmento idoso, que carrega histórias de vida marcadas pelas mazelas geradas pelo sistema de exploração do trabalho.

Já Beauvoir (1990) destaca que se a velhice é uma realidade que transcende a história, não é menos verdade que esse destino seja vivido de maneira variável, de acordo com as condições materiais de produção e reprodução social, que imprimem um estatuto social à velhice, ou estatutos diferenciados, conforme as classes, status e hierarquias sociais.

Vive-se numa sociedade que valoriza o consumo, gerando uma falsa valorização dos que possuem renda, mesmo mínima, como os idosos aposentados, os que recebem pensões ou benefícios. Presencia-se a venda de pacotes turísticos para a terceira idade, clínicas de rejuvenescimento, academias e clubes para este público etc. Entretanto, tal valorização não consegue esconder as desigualdades e diversidades das velhices, haja vista que esta etapa da vida humana é considerada como individual e heterogênea.

É importante ressaltar aqui que o aumento expressivo dessa população requer um atendimento voltado para esse público. Neste sentido, sugere-se a discussão urgente entre gestores e formuladores de políticas acerca do panorama dessa transição e das políticas sociais públicas de atenção ao idoso.

Não se pode deixar de salientar que tais políticas públicas em tempos atuais, conforme afirma Teixeira (2008), reproduzem uma cultura privacionista no enfrentamento dos problemas sociais, através das modalidades de trabalho social com idosos da filantropia, organizações não governamentais, empresas cidadãs, sendo tomadas como uma inovação gerencial nos cuidados institucionais a idosos. O Estado, por sua vez, incentiva tais modalidades, reduzindo suas responsabilidades e distribuindo-as com a sociedade civil, o mercado e a família.

O que se pode considerar é que há uma transferência das responsabilidades, por um envelhecimento dito saudável, para o indivíduo, a família e a sociedade, sendo este repasse uma expressão clara da desresponsabilização estatal, dado o enfrentamento das mazelas sociais trazidas e reproduzidas no envelhecimento da população.

Segundo Antunes (2000), faz-se necessária uma nova sensibilidade, capaz de valorizar a pessoa idosa, possível por meio da demolição das barreiras estabelecidas pela ordem do capital. Pois o envelhecimento é considerado uma problemática social no capitalismo, tendo em vista que a pessoa idosa perde a sua utilidade para o sistema, por conta da idade. Envelhecer nesta lógica é ser considerado improdutivo, é ter seu tempo de vida submisso ao tempo de trabalho, a sua valorização baseada num modo de produção explorador, pois

Temporalis, Brasília (DF), ano 20, n. 39, p. 163-176, jan./jun. 2020. | ISSN 2238-1856 
se não se gera lucro com a sua força de trabalho, não se tem valor. Cumpre efetuar uma análise da real situação desse segmento inserido neste modo de produção.

\section{IDOSO E MERCADO: A RELAÇÃO CAPITALISTA NO PROCESSO DE ENVELHECIMENTO POPULACIONAL}

Neste item busca-se analisar a atual situação do idoso diante do modo de produção capitalista, pois enquanto indivíduo, a pessoa idosa faz parte do complexo sistema de relações sociais desenvolvidos sob a égide do capital.

\section{Exploração da força de trabalho e envelhecimento}

O sistema socioeconômico capitalista é mantido e se reproduz através da exploração da força de trabalho. A sociedade se divide entre aqueles indivíduos que detêm a posse privada dos meios de produção, ou seja, todo o material necessário para produzir os bens de consumo imprescindíveis à sobrevivência; e aqueles que não possuem outra forma de se manter a não ser vendendo sua força de trabalho diariamente em troca de um salário (muitas vezes insuficiente para comprar o básico para ele e sua família). Assim sendo, na sociedade capitalista existe uma divisão social entre classes, entre dominados e dominantes. Aqui se utiliza a denominação de burguesia, em referência ao primeiro; e de trabalhadores, em referência ao segundo.

Embora existam diversas formas de exploração da força de trabalho no interior das unidades produtivas - fábricas, empresas em geral, lojas etc. -, desde os primórdios deste sistema a exploração recai sobre indivíduos que compõem faixas etárias diversas. A exploração do trabalho infantil ainda hoje é assunto em pauta, quanto se trata do trabalho em todo o mundo.

Porém, dificilmente se percebe a problematização da exploração da força de trabalho idosa. Talvez por se pensar que ao alcançar certa idade e tempo de serviço o indivíduo tenha direito à aposentadoria. Aqui se chama a atenção para o fato de que atualmente, em vários países, a aposentadoria já não mais garante à pessoa idosa a possibilidade do atendimento de suas necessidades básicas e que muitos destes beneficiários se veem obrigados a voltar ao mundo do trabalho.

Segundo a Secretaria da Previdência Social, no Brasil, em 2017, já se tinha em torno de 19 milhões aposentados, pelo Instituto Nacional de Seguridade Social (INSS); pelo menos 2/3 destes recebiam apenas um salário mínimo. Em pesquisa divulgada, em 2016, pelo Serviço de Proteção ao Crédito (SPC Brasil) e pela Confederação Nacional de Dirigentes Lojistas (CNDL), mais de $1 / 3$ das pessoas acima de 60 anos que já estão aposentadas no Brasil permanecem trabalhando. Isto em vínculos formais de trabalho, além daqueles que desenvolvem atividades no mercado informal. A pesquisa ainda informa que a renda insuficiente seria $o$ motivo de pelo menos $46,9 \%$ deles voltarem a trabalhar.

Além do envelhecimento populacional - tratado no item anterior -, a capacidade de alguns indivíduos de permanecerem trabalhando com 60 ou mais de 70 anos de idade vem sendo utilizada por governos, pela grande mídia e até por agências financeiras internacionais (tal como o Banco Mundial) a fim de justificar a possibilidade de aumentar a idade mínima para 


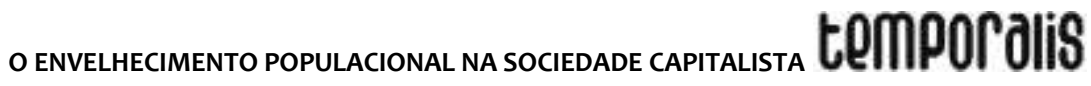

a concessão da aposentadoria pública. Como se as exceções pudessem servir de parâmetro e se transformar em regra.

De acordo com resultados de pesquisas do IBGE em 2016, a expectativa de vida foi de 75,8 anos para o total da população brasileira. Em comparativo com os dez anos anteriores, houve um aumento na média de 3,5 anos de expectativa de vida. Não apenas este aspecto, mas outros como o déficit nas contas públicas do sistema de previdência social brasileiro aumentam os argumentos a favor da reforma da política social de previdência social. Isso leva mais pessoas em contexto de envelhecimento a permanecer ofertando sua força de trabalho para a exploração capitalista.

O capital está se conseguindo explorar a força de trabalho das pessoas longevas, buscando aumentar o tempo da população economicamente ativa (tempo útil de vida no trabalho, com o aumento da idade mínima para a aposentadoria em todo o mundo), como também ciando e explorando novos nichos de mercado voltados para esta população enquanto consumidora. Assim, como trabalhador ativo ou como consumidor inativo, a pessoa idosa pode gerar lucro para o capital.

O que se quer destacar através dessa análise é que o sistema capitalista busca sempre expandir sua lucratividade por meio da exploração da força de trabalho de forma indiscriminada. Independentemente de idade, se puder trabalhar, o indivíduo é fonte de lucro. Isso é importante principalmente no momento de crise estrutural ${ }^{4}$ que atualmente se vivencia, pois possibilita a expansão e a acumulação do capital, bem como a ampliação do chamado exército industrial de reserva ${ }^{5}$, colocando à disposição mais pessoas para vender a sua força de trabalho.

\section{O mercado voltado para a população idosa}

Com o envelhecimento populacional das últimas décadas, no Brasil houve a ampliação de serviços demandados pela nova condição social. Alguns nichos de mercado se expandiram ou simplesmente ficaram mais valorizados (encarecidos), tanto na indústria quanto no varejo, tais como saúde e lazer.

Na nossa percepção, este envelhecimento populacional também foi possível devido aos avanços tecnológicos na área da saúde e à ampliação do acesso à política social pública de saúde. O desenvolvimento da medicina no tratamento e no combate efetivo de doenças infectocontagiosas diminuiu os índices de mortalidade. Outra contribuição decorreu do avanço da indústria farmacêutica em geral (através da biotecnologia e biossimilares), permitindo o barateamento de medicamentos, inclusive com a criação dos genéricos.

Porém, também este complexo médico-hospitalar se beneficia cada vez mais do aumento da expectativa de vida populacional, ampliando suas margens de lucratividade com o lançamento de produtos voltados para a população idosa. Os serviços médicos particulares

\footnotetext{
${ }^{4}$ Crise Estrutural, termo utilizado por István Mészáros (2009) para denominar um fenômeno global de crise econômica capitalista, iniciado em 1970 e que permanece até os dias atuais.

5 Exército industrial de reserva ou superpopulação relativa, termos utilizados por Karl Marx (1988) para designar o contingente populacional que não é absorvido pelo mercado de trabalho, mantendo-se desempregado e pauperizado.
}

Temporalis, Brasília (DF), ano 20, n. 39, p. 163-176, jan./jun. 2020. | ISSN 2238-1856 
destinados à população mais envelhecida sofrem reajustes acima do percentual de outras faixas etárias, pelo menos até o paciente completar 60 anos. Para pessoas com 60 anos ou mais, o reajuste de planos de saúde não é permitido por lei ${ }^{6}$. 0 crescimento de doenças devido à longevidade também aumenta, demandando, assim, um vasto espaço para a intervenção sanitária.

Apesar dos avanços na política pública de saúde no Brasil, com o Sistema Único de Saúde (SUS), nos últimos anos constata-se a ampliação dos serviços de saúde em âmbito privado. A precarização do serviço público, com equipamentos cada vez mais sucateados, morosidade burocrática, desabastecimento, cortes de financiamento etc., fortalece o processo de mercantilização dos serviços de saúde.

A adaptação do capital para aproveitar este espaço de mercado se dá mediante o crescimento dos planos de saúde e de serviços particulares. Segundo a Agência Nacional de Saúde Suplementar (2018), mais de 47 milhões de pessoas têm contratos de planos privados de assistência médica. De acordo com Oliveira, Veras e Cordeiro (2017), 12,6\% destes são idosos com 60 anos ou mais. Dados mais recentes, de maio de 2018, apontam que $22,7 \%$ da população brasileira tem a cobertura destes planos. Eram então 1.048 planos (de assistência médico-hospitalar e odontológica), e juntos estes planos somaram uma receita de mais de 45 bilhões de reais apenas no $1^{\circ}$ trimestre deste ano.

As cobranças mais elevadas desses serviços são justificadas pelas operadoras de saúde suplementar (privado) pela maior utilização dos serviços pelos idosos. De acordo com Oliveira, Veras e Cordeiro (2017), "[...] ao se tratar de indivíduos de maior idade, a tendência é que utilizem mais o sistema de saúde, havendo assim maior carga financeira quando utilizados os fatores moderadores" (Oliveira, Veras e Cordeiro, 2017, p. 627).

O complexo médico-hospitalar tem uma vasta demanda para explorar, que vai desde a oferta de insumos a unidades de serviços de saúde (público e privados); equipamentos de baixa, média e alta complexidade para realização de exames; cirurgias e tratamentos em geral, como também a indústria de medicamentos. Não apenas em âmbito privado, mas também em âmbito público, o lucro das grandes empresas de saúde se expande, pois para ofertar os serviços públicos o Estado se torna um grande consumidor dessas empresas.

A elevação do número de pessoas idosas no país reflete diretamente na economia, pois confere novas possibilidades de lucratividade ao mercado. Não apenas amplia a demanda para os serviços de saúde, como também traz à tona um novo consumidor, com um perfil próprio, mas essencial para o mercado. Todavia, é importante lembrar aqui que nem toda pessoa idosa terá acesso a esses serviços e seus altos custos.

Outro nicho de mercado em expansão devido ao envelhecimento populacional é a indústria de lazer, esportes e cultura. Serviços de convivência de idosos, excursões turísticas, esportes, eventos culturais voltados para a terceira idade têm sido mais procurados. $\mathrm{O}$

\footnotetext{
${ }^{6}$ A Lei n $9.656 / 98$ (BRASIL, 1998) proíbe reajuste das mensalidades de planos de saúde aos consumidores com mais de 60 anos, desde que participem do plano de saúde há mais de dez anos. Porém, com a homologação do Estatuto do Idoso, a partir de 2004 passou a ser proibido o aumento de mensalidade acima dos 60 anos, em razão da idade. A Agência Nacional de Saúde (ANS) criou nova norma, na qual foram padronizadas as faixas etárias.
}

Temporalis, Brasília (DF), ano 20, n. 39, p. 163-176, jan./jun. 2020. | ISSN 2238-1856 
papel das pessoas idosas como consumidor acaba sendo cada vez mais evidenciado pelo mercado em crise, na busca de novos espaços de acumulação e expansão de capitais.

Assim, a cultura, o lazer, o esporte, reificados como mercadoria, são "[...] trocados por prestígio, privilégio, bens materiais e até dinheiro, em vez de promover a satisfação de necessidades humanas, na perspectiva de uma melhor qualidade de vida e do aperfeiçoamento da cidadania" (FERRIGNO, 2016, p. 345). No sistema capitalista o objetivo é o lucro; dessa forma, tudo vira mercadoria. Na busca desses serviços, o idoso se torna um consumidor especial, principalmente porque a garantia do pagamento se expressa no acesso à sua aposentadoria, embora sabendo que esta, muitas vezes, não consegue suprir sequer as necessidades básicas da população idosa.

Visando à potencialidade deste mercado, “[...] a indústria do entretenimento se expande em todo o mundo e tem nos idosos um importante mercado consumidor, capaz ainda de muito crescimento. Assim como há lazer em todas as classes sociais, há também lazer em todas as faixas etárias, inclusive na velhice" (FERRIGNO, 2016, p. 349). O tempo livre proporcionado pela aposentadoria (para aqueles que realmente não continuam a trabalhar) instiga o idoso a buscar formas de lazer no mercado, seja através do teatro, cinema, entretenimento, cursos, turismo ou atividades físicas.

Diante de tais análises, indaga-se até que ponto será permissível o desenvolvimento da longevidade no nosso país diante das ações governamentais dos últimos anos. Com o fortalecimento de medidas neoliberais de diminuição dos gastos públicos na área social, as políticas sociais ficam cada vez mais precarizadas, voltando-se para a população mais empobrecida e abrindo espaço para a prestação dos serviços sociais pelo setor privado. Deixa-se de lado o fortalecimento do direito social, visando à ampliação do mercado.

Assim, em meio aos cortes de gastos na saúde promovidos pela Emenda Constitucional 95/2016 (BRASIL, 2016), é de se supor o aumento da precarização não apenas do setor público de saúde, mas também de diversas políticas sociais que até então contribuíam para o aumento da longevidade populacional brasileira. Isso pode resultar no retrocesso desse contexto social, ocasionando maiores índices de mortalidade.

\section{OS AVANÇOS E CONQUISTAS ALCANÇADOS PELA POPULAÇÃO IDOSA: POLÍTICAS SOCIAIS PÚBLICAS VOLTADAS AO IDOSO}

Diante do envelhecimento populacional e suas consequências debatidas até então, podese agora analisar os avanços decorrentes dos direitos sociais voltados para este segmento. Como destacam Camarano e Pasinato (2004), a partir da década de 1970 os programas sociais voltados para o envelhecimento começam a tomar expressão nos países desenvolvidos. Nesses países,

[...] o envelhecimento populacional ocorreu em um cenário socioeconômico favorável, o que permitiu a expansão dos sistemas de proteção social, que tinham como objetivo a manutenção do papel social dos idosos e/ou a sua reinserção, bem como a prevenção da perda de sua autonomia (CAMARANO; PASINATO, 2004, p. 24). 


\section{temporolis}

Já nos países em desenvolvimento, como o Brasil, o envelhecimento "[...] está ocorrendo em meio a uma conjuntura recessiva e a uma crise fiscal que dificultam a expansão do sistema de proteção social para todos os grupos etários e soma-se a uma ampla lista de questões sociais não resolvidas" (CAMARANO; PASINATO, 2004, p. 253-254).

Vale destacar dois marcos importantes para a inserção do envelhecimento no Estado Democrático de Direito e na agenda pública internacional, que trouxeram reflexos para o cenário nacional: a Assembleia Mundial sobre o Envelhecimento, na cidade de Viena, em 1982; e a Assembleia Mundial, ocorrida em Madri, no ano de 2002, ambas promovidas pela ONU. Camarano e Pasinato (2004) asseveram que a Assembleia de Viena resultou num plano de ação global e representou um avanço, colocando a questão do envelhecimento como foco de atenção, pois, até então, as questões sociais, como o envelhecimento, não recebiam a mesma ênfase que os temas econômicos e políticos.

Segundo tais autoras, uma das implicações da Assembleia de Madri foi um Plano de Ação com foco no desenvolvimento de uma política internacional para o envelhecimento no século XXI. A Assembleia adotou a Declaração Política e o Plano de Ação Internacional sobre o Envelhecimento. O Plano de Ação pedia mudanças de atitudes, políticas e práticas em todos os níveis, para satisfazer as enormes potencialidades do envelhecimento no século XXI. Suas recomendações específicas para ação davam prioridade às pessoas mais velhas e sua relação com o desenvolvimento, propondo melhorias na saúde e no bem-estar na velhice, assegurando habitação e ambientes de apoio.

Não se pode negar a presença e o domínio das ideias neoliberais nessa Assembleia, que exerceram uma significativa influência no gerenciamento das ações voltadas ao envelhecimento, secundarizando o papel do Estado e dividindo responsabilidades sociais, legitimando ações de outras instâncias que não a pública no trato das expressões da "questão social". Viabilizou assim a forte presença de organizações não governamentais e a colaboração estabelecida entre o Estado e a sociedade civil para garantir a proteção social (FERREIRA; TEIXEIRA, 2014).

Essas assembleias, juntamente com outros movimentos e transformações ocorridos posteriormente acerca da problemática do envelhecimento, principalmente na década de 1990, representaram uma preocupação crescente das nações com o envelhecimento da sua população, tendo em vista o alargamento do topo das suas pirâmides etárias, ou seja, o aumento do número de idosos.

Em nível nacional, a entrada do envelhecimento populacional na agenda das políticas públicas brasileiras foi gradativa e contou com vários sujeitos. Destacam-se duas iniciativas levadas a cabo nos anos 1960 e que tiveram impacto no desenvolvimento futuro das políticas brasileiras para a população idosa. A primeira delas foi a criação da Sociedade Brasileira de Geriatria e Gerontologia (SBGG), em 1961. A segunda teve início em 1963, por iniciativa do Serviço Social do Comércio (SESC) e seus programas pioneiros para a terceira idade, entre outros que mobilizaram os idosos e a sociedade e foram os difusores das recomendações internacionais das assembleias mundiais.

Mas, foi com a universalização da Seguridade Social, na Constituição Federal de 1988 (BRASIL, 1988), que a atenção à população idosa recebeu um grande avanço, porque, de acordo com Camarano e Pasinato (2004), vinculou a rede de proteção social ao direito de

Temporalis, Brasília (DF), ano 20, n. 39, p. 163-176, jan./jun. 2020. | ISSN 2238-1856 
cidadania, e não somente ao contexto estritamente social-trabalhista e assistencialista. Outro fator de extrema relevância, que assinala a sensibilidade do governo brasileiro no sentido de positivar e efetivar direitos à população idosa, e também evidencia o êxito dos movimentos e organizações nacionais em prol dos idosos, foi a aprovação da Política Nacional do Idoso (PNI), em 4 de janeiro de 1994 (Lei $n^{\circ} 8.842$ ), que assegura direitos sociais à pessoa idosa (BRASIL, 1994).

A Política Nacional do Idoso (PNI), embora seja um importante instrumento legal que amplia a proteção social para a população idosa, é mais uma política social afetada pelas reformas neoliberais baseadas no princípio da setorialização das políticas sociais e na privatização da execução das ações. O Estado passa a não ser prioritário como garantidor de direitos, repassando, em parte, sua responsabilidade para a sociedade civil, "[...] através de ações desenvolvidas por organizações não governamentais (ONGs), comunidade, família ou entes municipais" (TEIXEIRA, 2008, p. 266).

Alguns anos após a aprovação da Política Nacional do Idoso (BRASIL, 2003), houve a aprovação de uma legislação relativa à atenção destinada às pessoas idosas, que reforça as diretrizes contidas na PNI e unifica leis e políticas que até então permaneciam fragmentadas e setorializadas: o Estatuto do Idoso. Sancionado em $1^{\circ}$ de outubro de 2003 (Lei $n^{\circ} 10.741$ ) e elaborado com a contribuição de entidades de defesa dos direitos dos idosos, o Estatuto do Idoso é um importante instrumento de garantia de direitos alcançados por eles. "Trata-se de um mecanismo formal, legal, que visa garantir direitos elementares da existência, da integridade da vida e do corpo, e da dignidade [...]" (TEIXEIRA, 2008, p. 288-289) da pessoa idosa, considerada legalmente, para efeitos jurídicos, a partir dos 60 anos de idade.

Outra lei que confirma o processo de avanço do Estado brasileiro na defesa dos direitos da pessoa idosa, pelo menos em tese, tendo em vista que, na prática, a efetivação ainda é insatisfatória, é a Portaria $n^{\circ} 2.528$, que trata da Política Nacional de Saúde da Pessoa Idosa, aprovada em 19 de outubro de 2006 (BRASIL, 2006). Foi formulada pelo Ministério da Saúde em consonância com a Constituição de 1988 e dispôs como ações estratégicas: (a) Caderneta de Saúde da Pessoa Idosa - instrumento de cidadania com informações relevantes sobre a saúde da pessoa idosa, possibilitando melhor acompanhamento por parte dos profissionais de saúde; (b) Manual de Atenção Básica e Saúde para a Pessoa Idosa - para a indução de ações de saúde, tendo como referência as diretrizes contidas na Política Nacional de Saúde da Pessoa Idosa; (c) Programa de Educação Permanente a Distância implementa programa específico na área do envelhecimento e saúde do idoso, voltado aos profissionais que trabalham na rede.

Todas essas ações, iniciativas e políticas direcionadas à população idosa, resguardadas as suas limitações, são imperativas para essa esfera da população. No entanto, não se pode deixar de fazer referência aos desafios de se concretizar direitos e de consolidá-los, no contexto atual de políticas sociais sob os moldes neoliberais. Coloca-se, então, como um dos principais desafios universalizar e democratizar direitos que passam a ser administrados, cada vez com maior frequência, na esfera privada, e ainda a instância do mercado, onde só quem acessa os direitos é quem pode pagar por eles. 
Assim, as políticas sociais brasileiras, num contexto neoliberal que reorganiza as funções do Estado de modo a diminuir sua responsabilização com o atendimento das refrações da "questão social", por meio da diminuição dos gastos com as políticas sociais, apresentam aspectos negativos e consideráveis obstáculos na efetivação dos direitos dos idosos.

\section{CONSIDERAÇÕES FINAIS}

Atualmente, conta-se com poucas produções que abordam o processo do envelhecimento humano na perspectiva da totalidade social, muito embora não se negue a contribuição dos estudos realizados na área do conhecimento das disciplinas que compõem a Saúde Coletiva, com enfoques fundamentados nos postulados da epidemiologia, da demografia, da gerontologia e da geriatria.

Os atuais discursos, advindos do senso comum, sobre o envelhecimento são universalizantes e homogeneizadores, como, por exemplo, o da terceira idade tida como sinônimo de melhor idade e idade do lazer, mascarando-se as desigualdades e a heterogeneidade nas formas de envelhecer. Investe-se, assim, no discurso acerca do envelhecimento ativo na saúde de modo a dividir as responsabilidades pelo envelhecimento bem-sucedido com o próprio idoso e com a família cuidadora, entre outros sujeitos envolvidos.

Os principais resultados e discussões aqui expostos tratam de uma heterogeneidade de velhice, na qual homens e mulheres vivenciam essa fase da vida de maneira diversa e particular. Ou seja, as velhices demonstram uma heterogeneidade muito maior do que aquelas analisadas apenas pelos fatores físicos, biológicos e cronológicos. Há uma diversidade de velhices que é fundamentalmente condicionada pelo embate de classes, porquanto a velhice é marcada pela divisão entre as classes sociais.

O Estado pode ser reconhecido como aquele que promove as discrepâncias entre o direito legal e o direito real, quando não garante a efetivação das políticas em favor do segmento. Há, com isso, o sucateamento das políticas sociais e, consequentemente, a desqualificação dos profissionais ante o fenômeno do envelhecimento e seus desafios.

O ideal é que todos possam ter as condições de desenvolvimento respeitadas igualmente, para que sejam estimulados da mesma forma ao longo da vida, sem distinções entre homens e mulheres, sem diferenciação de sexo, idade e raça, podendo desenvolver suas potencialidades em qualquer fase de sua vida com condições equivalentes.

Destaca-se que novas demandas vão surgindo devido ao processo de envelhecimento. São formuladas respostas por meio de ações e políticas sociais, e essas, por sua vez, são fruto dos movimentos sociais. Ocorre nesse contexto a ampliação da esfera de direitos das pessoas idosas. No entanto, essa garantia de direitos nem sempre tem se efetivado. Um dos motivos da não efetivação dos direitos sociais das pessoas idosas está intimamente vinculado ao modo de produção capitalista e aos ditames do Estado neoliberal, que se desresponsabiliza quanto à sua intervenção no campo social, no tocante ao processo de envelhecimento. Observa-se que há um abismo entre a garantia desses direitos e sua efetivação em benefício das pessoas idosas. 


\section{REFERÊNCIAS}

AGÊNCIA NACIONAL DE SAÚDE SUPLEMENTAR (Brasil). Dados gerais. Brasília (DF), 2018. http://www.ans.gov.br/perfil-do-setor/dados-gerais. Acesso em: 9 jun. 2018.

ANTUNES, R. Adeus ao trabalho? Ensaio sobre as metamorfoses e a centralidade do mundo do trabalho. 7. ed. São Paulo: Cortez, 2000.

BEAUVOIR, S. de. A velhice. Trad. Maria Helena Franco Monteiro. Rio de Janeiro: Nova Fronteira, 1990.

BRASIL. [Constituição (1988)]. Constituição da República Federativa do Brasil: promulgada em 5 de outubro de 1988. 4. ed. São Paulo: Saraiva, 1990.

BRASIL. Emenda Constitucional № 95, de 15 de dezembro de 2016. Altera o ato das disposições constitucionais transitórias, para instituir o novo regime fiscal, e dá outras providências. Brasília (DF), 2016. Disponível em:

http://www.planalto.gov.br/ccivil_03/constituicao/emendas/emc/emc95.htm. Acesso em: 10 jul. 2018.

BRASIL. Lei $\mathbf{n}^{\circ} \mathbf{1 0 . 7 4 1}$, de 1 de outubro de 2003. Dispõe sobre o Estatuto do Idoso e dá outras providências. Brasília, 2003.

BRASIL. Lei $\mathbf{n}^{\circ} \mathbf{9 . 6 5 6}$, de 3 de julho de 1998. Dispõe sobre os planos e seguros privados de assistência à saúde. Brasília (DF), 1998. Disponível em:

http://www.camara.gov.br/sileg/integras/449960.pdf Acesso em: 10 jul. 2018.

BRASIL. Lei n. 8.842, de 4 de janeiro de 1994. Dispõe sobre a Política Nacional do Idoso, cria o Conselho Nacional do Idoso e dá outras providências. Brasília (DF), 2010.

BRASIL. Ministério da Saúde. Portaria GM n² 2.528, de 19 de outubro de 2006. Aprova a Política Nacional de Saúde da Pessoa Idosa - PNSI. Diário Oficial da União, Poder Executivo, Brasília (DF), 20 out. 2006.

CAMARANO, A. A.; PASINATO, M. T. O envelhecimento populacional na agenda das políticas públicas. Rio de Janeiro: IPEA, 2004.

FERREIRA, A. P.; TEIXEIRA, S. M. Direitos da pessoa idosa: desafios à sua efetivação na sociedade brasileira. Argumentum, Vitória, v. 6, n. 1, p. 160-173, jan./jun. 2014. P. 160-173. Disponível em: http://periodicos.ufes.br/argumentum/article/view/7486. Acesso em: 10 jul. 2018.

FERRIGNO, José Carlos. O Cidadão Idoso: consumidor e produtor cultural. In: ALCÂNTARA, Alexandre de Oliveira; CAMARANO, Ana Amélia; GIACOMIN, Karla Cristina (Org.). Política Nacional do Idoso: velhas e novas questões. Rio de Janeiro: IPEA, 2016.

HADDAD, E. G. M. A ideologia da Velhice. 2. ed. São Paulo: Cortez, 2016. 
HADDAD, E. G. M. O direito à velhice: os aposentados e a previdência social. São Paulo: Cortez, 2001.

INSTITUTO BRASILEIRO DE GEOGRAFIA E ESTATÍSTICA. Censo Demográfico 2012. Brasília (DF), 2012. Disponível em: http: //www.censo2012.ibge.gov.br. Acesso em: 10 jul. 2018.

LOUVISON, M. C. P.; ROSA, T. E. da C. Envelhecimento e políticas públicas de saúde da pessoa idosa. In: BERZINS, M. V; BORGES, M. C. (Org.). Políticas Públicas para um país que envelhece. São Paulo: Martinari, 2012.

MARX, K. O capital. Vol. I. Tomo I. Coleção Os Economistas. Trad. Regis Barbosa e Flávio R. Kothe. São Paulo: Nova Cultural, 1988.

MÉSZÁROS, I. A crise estrutural do capital. São Paulo: Boitempo, 2009.

OLIVEIRA, Martha; VERAS, Renato; CORDEIRO, Hésio. A Saúde Suplementar e o envelhecimento após 19 anos de regulação: onde estamos? Revista

Brasileira de Geriatria e Gerontologia, Rio de Janeiro, 2017.

PAIVA, Sálvea de Oliveira Campelo e. Envelhecimento, saúde e trabalho no tempo do capital. 1. ed. São Paulo: Cortez, 2014.

PAIVA, Sálvea de Oliveira Campelo e. Envelhecimento, saúde e trabalho no tempo do capital: um estudo sobre a racionalidade na produção de conhecimento do serviço social. 2012. Tese (Doutorado em Serviço Social)-Centro Ciências Sociais Aplicadas, Programa de Pós-Graduação em Serviço Social, Universidade Federal de Pernambuco,Recife, 2012.

PNUD. Relatório do Desenvolvimento Humano 2014: sustentar o progresso humano: reduzir as vulnerabilidades e reforçar a resiliência. New York, 2014. Disponível em: http://hdr.undp.org/sites/default/files/hdr2014_pt_web.pdf. Acesso em: 20 set. 2016.

TEIXEIRA, S. M. Envelhecimento na Sociabilidade do Capital. Campinas: Papel Social, 2017.

TEIXEIRA, S. M. Envelhecimento e trabalho no tempo de capital: implicações para a proteção social no Brasil. São Paulo: Cortez, 2008.

Milena da Silva SANTOS Pesquisadora e autora.

Bacharel em Serviço Social pela Universidade Federal de Alagoas (UFAL). Mestre em Serviço Social pela Universidade Federal de Alagoas (UFAL). Doutoranda do Programa de Pós-graduação em Serviço Social (PPGSS), da Universidade Federal do Rio Grande do Norte (UFRN).

Michelli Barbosa do NASCIMENTO Pesquisadora e autora.

Bacharel em Serviço Social pela Universidade Federal de Pernambuco (UFPE). Mestre em Gerontologia pela Universidade Federal de Pernambuco (UFPE). Assistente social do Programa Hospital do Casa/Hospital Agamenon Magalhães (Recife-PE). 